Publisher: Taylor \& Francis

Journal: Expert Opinion on Orphan Drugs

DOI: $10.1517 / 21678707.2016 .1128819$

Invited Review

\title{
Histaminergic modulation in Tourette syndrome
}

${ }^{1}$ Heart of England NHS Foundation Trust, Birmingham, UK

${ }^{2}$ School of Life and Health Sciences, Aston Brain Centre, Aston University, Birmingham, UK

${ }^{3}$ Children's Epilepsy Surgery Programme, The Birmingham Children's Hospital NHS Foundation Trust, Birmingham, UK

${ }^{4}$ Department of Neuropsychiatry, Birmingham and Solihull MentalHealth NHS Foundation Trust, Birmingham, UK

${ }^{5}$ Sobell Department of Motor Neuroscience and Movement Disorders, Institute of Neurology and UCL, London, UK

\section{*Correspondence:}

Prof Andrea E. Cavanna, MD PhD FRCP

Department of Neuropsychiatry

The Barberry National Centre for Mental Health

25 Vincent Drive

Birmingham B15 2FG

United Kingdom 
Email: a.e.cavanna@bham.ac.uk

Tel: +44 1213012280

\section{Acknowledgments and Disclosures}

JHC has no conflicts of interest to declare; SS has received unrestricted educational grants from Eisai Pharmaceuticals, UCB Pharma, and Beacon Pharmaceuticals Limited; AEC has received Board Membership fees and research grants from Eisai Pharmaceuticals and lectureship grants from Eisai Pharmaceuticals, UCB Pharma, and Janssen-Cilag. 
Invited Review

\section{Histaminergic modulation in Tourette syndrome}




\section{Abstract}

Introduction. Tourette syndrome is a neurodevelopmental disorder characterized by multiple motor tics and at least one vocal/phonic tic. Clinical phenotypes show a wide variability, often incorporating behavioral symptoms. The exact pathophysiology of Tourette syndrome is unknown, however genetic vulnerability and alterations in dopaminergic neurotransmission have consistently been reported. Other biochemical pathways, including histaminergic neurotransmission, are likely to be involved but have received relatively little attention until recently.

Areas covered. We conducted a systematic literature review focusing on the role of histaminergic neurotransmission and its pharmacological modulation in Tourette syndrome. We identified a number of relevant original studies published over the last five years, mainly focusing on genetic aspects.

Expert opinion. There is converging evidence from recent studies supporting the hypothesis that histaminergic neurotransmission may play a role in the pathophysiology of Tourette syndrome. Most studies focused on the role of the histidine decarboxylase gene and the potential usefulness of histidine decarboxylase knockout mice as an experimental model for studying neurochemical function in Tourette syndrome. There have been no large scale studies assessing the use of histaminergic medications in the management of Tourette syndrome. This would be an important area for future research, with direct implications for the clinical management of selected phenotypes.

Keywords: histamine, Tourette syndrome, tics, animal models, treatment 


\section{Introduction}

\subsection{Tourette Syndrome}

Tourette syndrome (TS), first described in the medical literature by French neurologist Georges Gilles de la Tourette in the second half of the XIX Century, is a neurodevelopmental disorder characterized by chronic motor and vocal tics [1-4]. Tics are defined as sudden, repetitive, non-rhythmic, involuntary movements and vocalizations [5]. The most common motor tics include eye blinking, facial grimacing, neck stretching, and shoulder shrugging, whereas vocal tics - more appropriately referred to as phonic tics as vocal chords are not always involved - are mainly represented by grunting, sniffing, and throat clearing [6]. Interestingly, tics are characteristically preceded by subjective urges which are relieved by tic expression and can be resisted only for a limited length of time, at the expense of mounting inner tension [7-12]. According to the DSM-5, diagnostic criteria for TS focus on the presence of multiple motor tics plus at least one vocal tic, with onset before the age of 18 years and lasting for over a year [13]. Based on epidemiological studies mainly carried out in school-age children, TS is thought to affect between $0.3 \%$ and $0.9 \%$ of the population, with a male-to-female ratio of $3-4: 1[6,14,15]$. Onset is typically in early childhood; one large multicenter study reported a mean age of onset of 6.4 years [16]. A considerable proportion of patients experience a decline in both the frequency and severity of their symptoms as they enter adult life [17]. Around $90 \%$ of patients with TS are diagnosed with co-morbid psychiatric disorders $[16,18,19]$. The most common behavioral co-morbidities are obsessivecompulsive disorder [20,21] and attention deficit and hyperactivity disorder [22,23], although

affective disorders [24] and impulse control disorders [25-27] have been reported more commonly in patients with TS than in the general population. 
The exact pathophysiological mechanisms underlying TS are unknown, however converging lines of evidence point to abnormally increased dopamine neurotransmission, particularly at the level of the basal ganglia and fronto-striatal circuitries [2,28-30]. This hypothesis is in line with evidence of altered structural connectivity within the cortico-striato-pallidothalamic circuitry [31]. As with other neurodevelopmental conditions, there is solid evidence for a genetic component to the expression of TS [32,33], thought to involve complex multigene changes [34]. TS has a heritability of approximately 0.58 [35] and its genetic heterogeneity has recently been confirmed by the results of recent large studies, which have failed to identify a single shared mutation or even common polymorphisms [36].

Environmental factors also play a role and autoimmune mechanisms haye been proposed to be involved at least in a subgroup of patients [37,38].

A proportion of patients with TS do not require intervention, however when tics and/or comorbid behavioral problems are considered physically, socially or emotionally disabling and cause functional impairment, active treatment can be implemented [39]. Management of TS is primarily pharmacological $[39,40]$, although behavioral therapies $[41,42]$ and neurosurgical interventions [43-45] have shown benefit in selected patients. Pharmacological agents belonging to a number of classes are routinely used in the treatment of TS, the most commonly prescribed being dopamine antagonists [46]. First-line treatment options often include either an alpha-adrenergic agonist such as clonidine [47] or atypical antipsychotic agents such as risperidone and aripiprazole [39]. Second-line options include old generation or typical neuroleptics, such as haloperidol and pimozide, with established efficacy but worse tolerability profiles [48]. In a number of cases polypharmacy is needed, alongside behavioral interventions, such as habit reversal training $[49,50]$, and, in refractory cases, deep brain stimulation [43-45]. 


\subsection{Dopaminergic and Histaminergic Pathways in Tourette Syndrome}

Although the majority of studies have supported the role of dopamine in TS, there is growing evidence for alterations across multiple biochemical systems [51,52], including abnormal histaminergic neurotransmission [53]. Histamine is an organic nitrogenous compound that acts as a signaling molecule in the immune and gastrointestinal systems, as well as a neurotransmitter within the central nervous system [54]. Histaminergic neurons mainly originate from the tuberomamillary nucleus of the hypothalamus [55], and their widespread projections reach most areas of the brain. Histamine acts through four receptors $(\mathrm{H} 1-\mathrm{H} 4)$ and actively regulates arousal, feeding, learning and memory processes [56,57]. $\mathrm{H} 1$ and $\mathrm{H} 2$ receptors are expressed throughout the central nervous system, $\mathrm{H} 3$ receptors are limited to the brain, and $\mathrm{H} 4$ receptors are primarily located in the immune system, with limited action on the brain $[58,59]$. Specifically, H3 receptors are found in high concentrations throughout the cortex, hippocampus and striatum [54], the latter of which has been strongly associated with TS pathophysiology. Moreover, $\mathrm{H} 3$ receptors in the striatum have been shown to have significant roles in modulating dopaminergic neurotransmission $[59,60]$, thus further supporting their possible role in TS [61]. Specifically, histamine neurotransmission appears to reduce the concentration of dopamine in the striatum by acting at $\mathrm{H} 3$ heteroreceptors on dopaminergic afferents. Through this action, histamine can exert control on the dopaminergic pathways targeting the GABAergic medium-spiny projection neurons that make up approximately $95 \%$ of all striatal neurons, thereby affecting the behaviour of the basal ganglia as a whole.

\subsection{Histaminergic Neurotransmission and Neuropsychiatric Disorders}


Alterations in histaminergic pathways are known to have far-reaching consequences and it is therefore not surprising that histamine neurotransmission has been implicated in a number of neurological conditions [62-66]. For example, in post-mortem studies of patients with Alzheimer disease, levels of histamine were reduced in the hypothalamus, hippocampus and temporal lobes when compared to controls [67]. Histamine has also been shown to decrease neurotoxicity produced by $\beta$-amyloid in Alzheimer disease, a process that appears to be regulated by the $\mathrm{H} 2$ and $\mathrm{H} 3$ receptor subtypes. Overall, $\mathrm{H} 3$ receptors have also been implicated in suppressing histamine release in the brain. Therefore, pharmacological agents known to antagonize the $\mathrm{H} 3$ receptor and to regulate the $\mathrm{H} 2$ receptor have been proposed as promising treatment avenues for patients with Alzheimer disease [68]. Likewise, reduced histamine levels have also been demonstrated after bilateral carotid artery occlusion in rats, suggesting a potential role in vascular dementia [69]. Furthermore, patients with Parkinson disease, but not those with more severe forms of 'Parkinson-plus' conditions such as multiple system atrophy, were found to have increased levels of brain histamine [70]. Finally, low histamine levels have been documented in patients with epilepsy and $\mathrm{H} 3$ receptor blockade (which increases endogenous brain histamine release) has been reported to increase seizure threshold [71]. Studies investigating the role of other histamine receptors have produced mixed results [72].

\subsection{Systematic Literature Review}

This article will systematically review the current evidence for the role of histaminergic neurotransmission in TS. In order to comprehensively identify relevant articles within this dynamic research area, the PRISMA guidelines for reporting systematic literature reviews [73] were followed. Both PubMed and PsycInfo databases were searched using the search 
terms tourett* OR tic* AND histamin* and limited to English language. After removing duplicates and studies not focusing on histamine and/or TS, the authors manually screened the abstracts of the remaining articles for relevance to histaminergic neurotransmission in TS, and identified the studies that are included in this review. 


\section{Tourette Syndrome and Histaminergic Neurotransmission}

\subsection{Clinical Studies}

A small number of original studies have been carried out to specifically investigate the role of histamine neurotransmission in TS. A genetic linkage study carried out on a family with an unusually high prevalence of TS provided initial evidence of a possible role of histaminergic dysfunction [74]. DNA samples from all family members in the two-generation pedigree were obtained and genotyped. The father and all eight offspring met the DSM-IV-TR diagnostic criteria for TS [75], whereas the mother and extended family were apparently free from tics or other symptoms of TS. In terms of TS-related behavioral symptoms, the father and two children also had obsessive-compulsive disorder. This family showed a Mendelian pattern of autosomal dominant inheritance, which is rarely seen in TS. Polymerase chain reaction $(\mathrm{PCR})$ analyses identified a premature termination codon $(\mathrm{W} 317 \mathrm{X})$ on exon 9 of the histidine decarboxylase (HDC) gene, which was present in the father and offspring, but absent in the mother. This termination codon resulted from a guanine-to-adenosine transition at the nucleotide 951 position of the gene, leading to a complete loss of enzyme function. The HDC gene codes for the enzyme histidine decarboxylase, a rate-limiting enzyme in the biosynthesis of histamine from L-histidine [53]. These findings therefore suggested a potential role for HDC deficiency in the pathophysiology of TS through impairment of histamine neurotransmission. However, the inheritance pattern in this family is uncommon for TS, and a mutation screening of Chinese Han patients did not support the link between the aforementioned gene and TS [76].

In 2012, a case-control study of 460 patients with TS focused on copy number variants (CNVs) to identify risk regions or molecular pathways which may be associated with TS [77]. The authors found no statistically significant increase in CNVs when comparing 
patients with TS to controls, however there was some overlap between CNVs found in patients with TS and those previously identified in autism spectrum disorder. Moreover, pathway analysis showed enrichment of genes within the $\mathrm{H} 1$ and $\mathrm{H} 2$ receptor signaling pathways. Presynaptic receptors in these pathways regulate release of histamine and of other neurotransmitters such as dopamine, suggesting wider neural signaling abnormalities in TS. A limiting factor of this study was the relatively small sample size compared to similar CNV analyses in other patient cohorts.

The identification of the previously mentioned HDC mutation led to a study in 2013 that investigated variations across the whole HDC gene [78]. This study involved 520 families with TS from seven European Countries. Genotyping studies found strong over-transmission of alleles at two single nucleotide polymorphisms (rs854150 and rs1894236). These results confirmed a putative role for histamine pathways in neuronal development, and provided further support to the hypothesis that dysfunction in these pathways may be involved in development of TS at least in a subgroup of patients.

\subsection{The HDC Knockout Mouse Model}

HDC deficiency was investigated in a recent study [79] using a HDC knockout model. Although mice which are deficient in the HDC gene do not exhibit detectable tic-like movements at baseline, when challenged with either high-dose psychostimulants or acute stress they develop repetitive purposeless movements (e.g. focused sniffing, orofacial movements, excessive grooming) that may resemble tic symptoms. Clearly no animal model can capture all aspects of the complex phenomenology of TS, however these behavioral phenotypes were thought to be qualitatively different to the increased locomotion upon stimulant administration and amphetamine-induced stereotypies observed in healthy mice. 
Interestingly, these tic-like behaviors could be alleviated by repletion of histamine via intracerebral infusion. Furthermore, striatal dopamine levels appeared to be negatively regulated by histamine, as the HDC knockout mice exhibited increased dopamine turnover. In consideration of the known role of increased dopamine neurotransmission in the pathophysiology of TS, these results provided in vivo experimental evidence of a direct relationship between histamine and dopamine regulation in the basal ganglia. Interestingly, it was noted that the decrease or disappearance of tics in patients with TS parallels the circadian pattern of histamine. The histaminergic neurons projecting from the tuberomamillary nucleus of the hypothalamus to a wide range of brain structures, including the striatum, fire at high frequency during wakefulness and are virtually silent during sleep. The possibility that histamine exerts a diurnal control on the activity of the basal ganglia circuitry would be in line with the known fluctuations in tic expression (waxing and waning during day time and decrease/remission during night time). The authors of these experiments acknowledged the possibility that the HDC knockout mouse model might be representative of a relatively rare pathophysiological mechanism for TS and that this might therefore be relevant to only a small proportion of patients with TS. However, these findings led to the suggestion that increasing brain histamine could potentially be of therapeutic benefit, and that dietary supplementation with histidine may increase histamine production.

The HDC knockout mouse model was also used in a further study from 2014 analyzing changes in signaling pathways in the striatal cells in comparison to animals [80]. The study found that levels of dopamine were higher in the HDC knockout mice, and there were also alterations to protein kinase B Akt and mitogen-activated protein kinase (MAPK) signaling pathways. The changes discovered in these pathways are characteristic of the effects of dopamine on striatal neurons. Furthermore, the investigators identified glycogen synthase kinase 3 beta (GSK3 3$)$ as a potential therapeutic target due to its role in the AKT pathway. 
Since the first reports of a possible association between HDC deficiency and TS, the HDC knockout mice paradigm has been used in multiple studies as an experimental model of TS. This model opened promising avenues, as HDC knockout mice show a phenotype that shares some components with the symptoms of patients with TS [81]. Specifically, the study by Castellan Baldan et al. [79] provided evidence for disturbed sensorimotor gating in HDC knockout mice, as indicated by reduced pre-pulse inhibition (a neurophysiological phenomenon in which a weak pre-stimulus sound inhibits the reaction to a subsequent strong startling stimulus). Reduction in pre-pulse inhibition was also observed in patients with TS carrying the HDC W317X mutation [74], presumably as a result of elevation of striatal dopamine levels [82], which is in turn caused by a lack of inhibitory effect of histamine on dopamine release. This hypothesis was confirmed by the findings of the study by Castellan Baldan et al. [79], who directly determined striatal dopamine using micro-dialysis: during the night-phase, when mice become active, striatal levels of histamine were found to be increased in wild-type mice, but not in HDC knockout mice; conversely, dopamine levels were significantly higher during the night phase in HDC knockout mice as compared to wild-type controls [79]. The inhibitory effect of histamine was further demonstrated by histamine infusion into wild-type mice, resulting in a significant reduction in striatal dopamine compared to saline controls [79]. Finally, both patients with TS carrying the HDC W317X mutation and HDC knockout mice showed an upregulation of dopamine D2 and D3 receptors in the substantia nigra, as determined by positron emission tomography in the patients with TS using 11C-labeled 4-propyl-9-hydroxynaphthoxazine binding or by 3H-raclopride binding to brain slices of HDC knockout mice [79]. Taken together, these findings suggested that HDC knockout mice may represent a valid animal model for human TS, although the tic-like repetitive behaviors (e.g. sniffing-like head movements) observed in HDC knockout mice in the study by Castellan Baldan et al. [79] were not observed at baseline, but emerged after 
acute challenge with the psychostimulant amphetamine (and were completely eliminated by pretreatment with either haloperidol or histamine). The fact that amphetamine was necessary to induce a tic-like phenotype in HDC knockout mice brought further evidence to suggest that these animal models are only partly comparable to patients with TS, who display symptoms without pharmacological challenge. A recent study by Xu et al. [83] tested the ability of an acute stressor to stimulate repetitive behaviors in this experimental model using tone fear conditioning. HDC knockout mice acquired conditioned fear normally, as manifested by freezing during the presentation of a tone 48 hours after it had been paired with a shock. During the 30 minutes following tone presentation, knockout mice showed increased grooming, whereas heterozygote mice exhibited normal freezing and intermediate grooming. These data validated a new paradigm for the examination of tic-like repetitive behaviors in animals without pharmacological challenge and enhanced the face validity of HDC knockout mice as a pathophysiologically grounded model of tic disorders.

\subsection{Pharmacological Modulation}

At present, no large-scale clinical trials of histaminergic modulators have been undertaken in the TS patient population. A preliminary report from 1986 presented a small case series of three patients with TS where use of antihistaminergic agents exacerbated tics [84]. Caution is required when interpreting these findings, also in consideration of the non-selectivity (anticholinergic properties etc.) of antihistaminergic medications in clinical use. More recently, a case report published in 2012 presented the case of a male patient with TS and comorbid narcolepsy [85]. This patient's condition had proven refractory to treatment with a number of antidopaminergic medications. Based on the findings of the study by ErcanSencicek et al. [74], the patient underwent a trial with the $\mathrm{H} 3$ receptor inverse agonist 
pitolisant. The authors found that pitolisant significantly decreased daytime sleepiness without worsening in tic severity, a common side effect associated with other psychostimulants such as methylphenidate and modafinil. However, contrary to what could be expected based on the histamine hypothesis of tics, the administration of pitolisant resulted in no significant improvement in tic severity. The authors considered that the lack of tic worsening in a sensitive patient (who had experienced worsening of tics on both methylphenidate and modafinil) warranted a controlled clinical trial of $\mathrm{H} 3$ receptor reverse agonists in patients with TS, particularly in the presence of co-morbid attention deficit hyperactivity disorder. It should be noted however that stimulant medications are not consistently associated with tic exacerbations, especially if administered in lower doses and with gradual titration $[86,87]$. Further supported by results of a positron emission tomography study assessing the novel $\mathrm{H} 3$ receptor antagonist AZD5213 [88], a randomized-controlled trial assessing its use has been undertaken, but as yet no results have been published (ClinicalTrials.gov: NCT01904773).

There is evidence that histamine can directly control striatal neurons by affecting the activity of multiple neurotransmitters which are supposed to play a role alongside dopamine in the pathophysiology of TS [51-53]. Histamine can modulate the intrinsic electrical properties of striatal cholinergic interneurons and negatively regulate the release of GABA from striatal medium-spiny projection neurons by acting at the level of $\mathrm{H} 3$ heteroreceptors. Through the same mechanism, histamine can also modulate glutamatergic neurotransmission by decreasing the release of glutamate from striatal synaptosomes and reducing the electrically evoked glutamatergic field responses. Finally, it is possible that the histaminergic action affects other striatal neuromodulatory pathways, such as the noradrenergic and serotoninergic pathways, which would allow for complex interactions amongst neuromodulators, thus expanding the spectrum of potential pharmacological targets for TS. 


\section{Expert Opinion}

\subsection{Promising Avenues for Research}

Our systematic literature review was able to identify a small number of original studies specifically investigating histaminergic neurotransmission in TS. Interest in this topic was first generated by the report that a rare mutation in the HDC gene (W317X) was associated with the occurrence of TS in a two-generation pedigree [74]. Patients with the W317X mutation of HDC are unable to synthesize histamine and depend on the activity of HDC encoded by the non-mutated second allele. The presence of specific psychiatric comorbidities in some male members of this pedigree could also be explained by a dysfunction in the histaminergic system, as overriding inhibition of competing pathways within parallel cortico-striato-thalamo-cortical loops can hinder behavioral switching as seen in obsessivecompulsive disorder [89]. A more general association of histaminergic pathways with TS was identified by analysis of rare CNVs in a subsequent study [77]. The hypothesis of an involvement of the histaminergic system in the pathogenesis of TS was also supported by a more recent report on single nucleotide polymorphisms in the HDC region that are associated with TS [78]. However, HDC mutations were not replicated in larger scale studies [76], suggesting that these genetic alterations may only be responsible for a subset of patients with TS. Interestingly, we have recently seen increasing consensus that TS is a heterogeneous condition from both the phenotypic and genotypic points of view. Studies conducted using principal-component factor analysis [90-95], hierarchical cluster analysis $[90,93,94,96]$ and latent class analysis $[97,98]$ have identified a number of clinical phenotypes which, if

replicated, could prompt further research into individual genotype correlates. Perhaps the main limitation in our understanding of the role of histaminergic neurotransmission for the pathophysiology of TS is its limited generalizability, since a significant proportion of patients with TS have not shown any alterations in the HDC gene, indicating that this might be a rare 
pattern of TS inheritance. Further exploration of the role of histaminergic transmission in TS might still offer some insight if associated with careful stratification of patients by specific behavioral and intermediate phenotypes within the TS spectrum. Based on the reviewed evidence, these points should stand as key lessons for the industry. In order to increase the knowledge base in this area, further research into other areas of histaminergic neurotransmission should be conducted. Examples may include comparing brain histamine levels in large cohorts of patients with TS and healthy controls, or carrying out further gene identification studies. Functional molecular neuroimaging studies may also provide a promising avenue of research.

If alterations in histaminergic neurotransmission are identified in a large cohort of patients with TS, this might have a significant payback in the design of novel classes of medications that modulate histamine and carry direct therapeutic implications. Based on current evidence, patients with TS associated with HDC deficiency may benefit from pharmacological histamine modulation, particularly involving agents acting on the $\mathrm{H} 3$ receptor. Expression of $\mathrm{H} 3$ receptors has been reported to be elevated in the HDC knockout model of TS at the level of the basal ganglia [99], a key region for the pathophysiology of TS, as altered striatal histaminergic-dopaminergic tone has been shown to potentially result in tic generation [89]. $\mathrm{H} 3$ receptors are thought to be localized primarily presynaptically, both as autoreceptors on histaminergic terminals, where they may play a role in negative feedback regulation of histamine release, and as a heteroreceptors on dopaminergic, glutamatergic and cholinergic neurons. Moreover the expression of this receptor is largely specific to the central nervous system, indicating that it could be pharmacologically targeted with minimal concern about peripheral side effects. Although pilot clinical studies in narcolepsy, schizophrenia and attention deficit disorder have yielded mixed results (with more favorable outcomes in conditions characterized by hypersomnia), preclinical evidence strongly suggests that $\mathrm{H} 3$ 
antagonism could open novel therapeutic avenues in TS and other neuropsychiatric disorders [99]. Specifically, the use of $\mathrm{H} 3$ antagonists could be assessed either as a monotherapy or in combination therapy for patients already taking medication, with the goal of expanding the relatively narrow range of safe and effective pharmacological options currently available to clinicians treating patients with TS $[39,40,100]$. Further implications of additional research into this field may include identification of families at risk of TS. Although TS is not known to shorten life expectancy, it can be highly detrimental to patients' health-related quality of life and psychosocial wellbeing [101-103]. Finally, recent observations that patients with TS can be prone to develop allergy related to histamine-associated immunological reactions prompt further investigations into the relationship between allergy, histamine and TS [104].

\subsection{Preliminary Conclusions}

In conclusion, although the results of a number of small scale studies support the hypothesis that histaminergic neurotransmission may play a role in the pathophysiology of TS, the majority of research has focused on the role of the HDC gene and there have been no large scale studies assessing the use of histaminergic medications in the management of TS. The wide phenotypic heterogeneity that characterizes TS poses as a significant challenge; however recent research has paved the way for further work into the identification of more precise genotype-phenotype correlations. Histaminergic neurotransmission is an area of interest for future research, with potential to impact the management and treatment of patients in the long term. 


\section{Declaration of interest}

A Cavanna has received board member fees and research grants from EISAI Pharmaceuticals and lectureship grants from EISAI Pharmaceuticals, UCB Pharma and Janssen-Cilag. S Seri has received unrestricted educational grants from EISAI Pharmaceuticals, UCB Pharma and Beacon Pharmaceuticals Ltd. The authors have no other relevant affiliations or financial involvement with any organization or entity with a financial interest in or financial conflict with the subject matter or materials discussed in the manuscript. This includes employment, consultancies, honoraria, stock ownership or options, expert testimony, grants or patents received or pending, or royalties. 


\section{References}

[1] Rickards H, Cavanna AE. Gilles de la Tourette: the man behind the syndrome. J

Psychosom Res 2009;67:469-74.

[2] Jankovic J, Kurlan R. Tourette syndrome: evolving concepts. Mov Disord 2011;26:11491156.

[3] McNaught KS, Mink JW. Advances in understanding and treatment of Tourette syndrome. Nat Rev Neurol 2011;7:667-676.

[4] Cavanna AE, Seri S. Tourette's syndrome. Br Med J 2013;347:f4964.

[5] Ganos C, Martino D. Tics and Tourette syndrome. Neurol Clin 2015;33:115-136.

[6] Martino D, Madhusudan N, Zis P, Cavanna AE. An introduction to the clinical phenomenology of Tourette syndrome. Int Rev Neurobiol 2013;112:1-32.

[7] Woods DW, Piacentini J, Himle MB, Chang S. Premonitory Urge for Tics Scale (PUTS): initial psychometric results and examination of the premonitory urge phenomenon in youths with tic disorders. J Dev Behav Pediatr 2005;26:397-403.

[8] Steinberg T, Shmuel Baruch S, Harush A, et al. Tic disorders and the premonitory urge. J Neural Transm 2010;117:277-84

[9] Rajagopal S, Seri S, Cavanna AE. Premonitory urges and sensorimotor processing in Tourette syndrome. Behav Neurol 2013;27:65-73.

[10] Crossley E, Cavanna AE. Sensory phenomena: Clinical correlates and impact on quality of life in adult patients with Tourette syndrome. Psychiatry Res 2013;209:705-10. 
[11] Crossley E, Seri S, Stern JS, Robertson MM, Cavanna AE. Premonitory urges for tics in adult patients with Tourette syndrome. Brain Dev 2014;36:45-50.

[12] Eddy CM, Cavanna AE. Premonitory urges in adults with complicated and uncomplicated Tourette syndrome. Behav Modif 2014;38:264-75.

[13] American Psychiatric Association. Diagnostic and statistical manual of mental disorders: 5th edition (DSM-5). Arlington, VA: American Psychiatric Publishing, 2013.

[14] Robertson MM, Eapen V, Cavanna AE. The international prevalence, epidemiology and clinical phenomenology of Tourette syndrome: a cross-cultural perspective.J Psychosom Res 2009;67:475-83.

[15] Scharf JM, Miller LL, Gauvin CA, Alabiso J, Mathews CA, Ben-Shlomo Y. Population prevalence of Tourette syndrome: a systematic review and meta-analysis. Mov Disord 2015;30:221-8.

*[16] Freeman RD, Fast DK, Burd L, Kerbeshian J, Robertson MM, Sandor P. An international perspective on Tourette syndrome: selected findings from 3,500 individuals in 22 countries. Dev Med Child Neurol 2000;42:436-47.

Largest study to date on the clinical phenotype of Tourette syndrome, encompassing tics and behavioral co-morbidities.

[17] Hassan N, Cavanna AE. The prognosis of Tourette syndrome: implications for clinical practice. Funct Neurol 2012;27:23-7.

[18] Robertson MM. Gilles de la Tourette syndrome: the complexities of phenotype and treatment. Br J Hosp Med 201 1;72:100-107. 
[19] Cavanna AE, Rickards HE. The psychopathological spectrum of Gilles de la Tourette syndrome. Neurosci Biobehav Rev 2013;37:1008-15.

[20] Lombroso PJ, Scahill L. Tourette syndrome and obsessive-compulsive disorder. Brain Dev 2008;30:231-7.

[21] Eddy CM, Cavanna AE. Tourette syndrome and obsessive compulsive disorder: Compulsivity along the continuum. J Obsessive Compuls Relat Disord 2014;3:363-71.

[22] El Malhany N, Gulisano M, Rizzo R, Curatolo P. Tourette syndrome and comorbid ADHD: causes and consequences. Eur J Pediatr 2014;174:279-88.

[23] Simpson HA, Jung L, Murphy TK. Update on attention-deficit/hyperactivity disorder and tic disorders: a review of the current literature, Curr Psychiatry Rep 2011;13:351-6.

[24] Robertson MM. Mood disorders and Gilles de la Tourette's syndrome: an update on prevalence, etiology, comorbidity, clinical associations, and implications. J Psychosom Res 2006;61:349-58.

[25] Frank M, Piedad J, Rickards H, Cavanna AE. The role of impulse control disorders in Tourette syndrome: an exploratory study. J Neurol Sci 2011;310:276-8.

[26] Wright A, Rickards H, Cavanna AE. Impulse control disorders in Gilles de la Tourette syndrome. J Neuropsychiatry Clin Neurosci 2012;24:16-27.

[27] Cox JH, Cavanna AE. Irritability symptoms in Gilles de la Tourette syndrome. J Neuropsychiatry Clin Neurosci 2015;27:42-7.

[28] Felling RJ, Singer HS. Neurobiology of Tourette syndrome: current status and need for further investigation. J Neurosci 2011;31:12387-95. 
[29] Singer HS. Tourette syndrome and other tic disorders. Handb Clin Neurol 2011;100:641657.

[30] Bronfeld M, Bar-Gad I. Tic disorders: what happens to the basal ganglia? Neuroscientist 2013;19:101-8.

[31] Worbe Y, Marrakch-Kacem L, Lecomte S, Valabregue R, Poupon F, Guevara P et al. Altered structural connectivity of cortico-striato-pallido-thalamic networks in Gilles de la Tourette syndrome. Brain 2015;138(2):472-82

[32] Deng H, Gao K, Jankovic J. The genetics of Tourette syndrome. Nat Rev Neurol 2012;8:203-13.

[33] Ali F, Morrison KE, Cavanna AE. The complex genetics of Gilles de la Tourette syndrome: implications for clinical practice. Neuropsychiatry 2013;3:321-30.

[34] Dietrich A, Fernandez TV, King RA, et al. The Tourette International Collaborative Genetics (TIC Genetics) study, finding the genes causing Tourette syndrome: objectives and methods. Eur Child Adolesc Psychiatry 2015;24:141-51.

[35] Davis LK, Yu D, Keenan CL, Gamazon ER, et al. Partitioning the heritability of Tourette syndrome and obsessive compulsive disorder reveals differences in genetic architecture. PLoS Genet 2013;9:e1003864.

[36] Scharf JM, Yu D, Mathews CA, et al. Genome-wide association study of Tourette's syndrome. Mol Psychiatry 2013;18:721-8. 
[37] Madhusudan N, Cavanna AE. The role of immune dysfunction in the development of tics and susceptibility to infections in Tourette syndrome: A systematic review. Basal Ganglia 2013;3:77-84.

[38] Martino D, Zis P, Buttiglione M. The role of immune mechanisms in Tourette syndrome. Brain Res 2015;1617:126-43.

[39] Roessner V, Plessen KJ, Rotherberger A, et al. European clinical guidelines for Tourette syndrome and other tic disorders. Part II: pharmacological treatment. Eur Child Adolesc Psychiatry 2011;20:173-96.

[40] Waldon K, Hill S, Termine C, Balottin U, Cavanna AE. Trials of pharmacological interventions for Tourette syndrome: a systematic review. Behav Neurol 2013;26:265-73.

[41] Frank M, Cavanna AE. Behavioural treatments for Tourette syndrome: an evidencebased review. Behav Neurol 2013;27:105-17.

[42] McGuire JF, Piacentini J, Brennan EA, et al. A meta-analysis of behavior therapy for Tourette Syndrome. J Psychiatr Res 2014;50:106-112.

[43] Porta M, Sassi M, Ali F, Cavanna AE, Servello D. Neurosurgical treatment for Gilles da la Tourette syndrome: the Italian perspective. J Psychosom Res 2009;67:585-90.

[44] Cavanna AE, Eddy CM, Mitchell R, et al. An approach to Deep Brain Stimulation for severe treatment-refractory Tourette syndrome: the UK perspective. Br J Neurosurg 2011;25:38-44.

[45] Schrock LE, Mink JW, Woods DW, et al. Tourette syndrome deep brain stimulation: a review and updated recommendations. Mov Disord 2015;30:448-71. 
[46] Thomas R, Cavanna AE. The pharmacology of Tourette syndrome. J Neural Transm 2013;120:689-94.

[47] Cavanna AE, Selvini C, Termine C, Balottin U, Eddy CM. Tolerability profile of clonidine in the treatment of adults with Tourette syndrome. Clin Neuropharmacol 2012;35:269-72.

[48] Gulisano M, Calì PV, Cavanna AE, Eddy C, Rickards H, Rizzo R. Cardiovascular safety of aripiprazole and pimozide in young patients with Tourette syndrome. Neurol Sci 2011;32:1213-7.

[49] Himle MB, Woods DW, Piacentini JC, Walkup JT. Brief review of habit reversal training for Tourette syndrome. J Child Neurol 2006;21:719-25.

[50] Dutta N, Cavanna AE. Effectiveness of Habit Reversal Therapy in the treatment of Tourette syndrome and other chronic tic disorders: a systematic review. Funct Neurol 2013;28:7-12.

[51] Steeves TD, Fox SH. Neurobiological basis of serotonin-dopamine antagonists in the treatment of Gilles de la Tourette syndrome. Prog Brain Res 2008;172:495-513.

[52] Wong DF, Brasić JR, Singer HS, et al. Mechanisms of dopaminergic and serotonergic neurotransmission in Tourette syndrome: clues from an in vivo neurochemistry study with PET.Neuropsychopharmacology 2008;33:1239-51.

[53] Udvardi PT, Nespoli E, Rizzo F, Henger F, Ludolph G. Nondopaminergic neurotransmission in the pathophysiology of Tourette syndrome. Int Rev Neurobiol 2013;112:95-130. 
[54] Haas HL, Sergeevva OA, Sebach O. Histamine in the nervous system. Physiol Rev 2008;88:1183-241.

[55] Panula P, Airaksinen MS, Pirvola U, Kotilainen E. A histamine-containing neuronal system in human brain. Neuroscience 1990;34:127-32.

[56] Brown RE, Stevens DR, Haas HL. The physiology of brain histamine. Prog Neurobiol 2001;63:637-72.

[57] Kohler CA, da Silva WC, Benetti F, Bonini JS. Histaminergic mechanisms for modulation of memory systems. Neural Plast 2011;2011:328602.

[58] Flik G, Dremencov E, Cremers TI. The role of cortical and hypothalamic histamine-3 receptors in the modulation of central histamine neurotransmission: an in vivo electrophysiology and microdialysis study. Eur J Neurosci 2011;34:1747-1755

[59] Ferrada C, Ferre S, Casado V, et al. Interactions between histamine H3 and dopamine D2 receptors and the implications for striatal function. Neuropharmacology 2008;55:190-7.

[60] Ellenbroek BA. Histamine $\mathrm{H} 3$ receptors, the complex interaction with dopamine and its implications for addiction. Br J Pharmacol 2013;170:46-57.

[61] Hallett M. Tourette syndrome: update. Brain Dev 2015;37:651-5.

[62] Nuutinen S, Panula P, Thurmond RL. Histamine in neurotransmission and brain diseases. Adv Exp Med Biol 2010;709:95-107.

[63] Baronio D, Gonchoroski T, Castro K, Zanatta G, Gottfried C, Riesgo R. Histaminergic system in brain disorders: lessons from the translational approach and future perspectives. Ann Gen Psychiatry 2014;13:34. 
[64] Bañuelos-Cabrera I, Valle-Dorado MG, Aldana BI, Orozco-Suárez SA, Rocha L. Role of histaminergic system in blood-brain barrier dysfunction associated with neurological disorders. Arch Med Res 2014;45:677-86.

[65] Shan L, Bao AM, Swaab DF. The human histaminergic system in neuropsychiatric disorders. Trends Neurosci 2015;38:176-7.

[66] Shan L, Dauvilliers Y, Siegel JM. Interactions of the histamine and hypoeretin systems in CNS disorders. Nat Rev Neurol 2015;11:401-13.

[67] Panula P, Rinne J, Kuokkanen K, et al. Neuronal histamine deficit in Alzheimer's disease. Neuroscience 1998;82:993-7.

[68] Naddafi F, Mirshafiey A. The neglected role of histamine in Alzheimer's Disease. Am J Alzheimers Dis Other Demen 2014;28:327-36.

[69] Stasiak A, Mussur M, Unzeta M, Lazewska D, Kiec-Kononowicz K, Fogel WA. The central histamine level in rat model of vascular dementia. J Physiol Pharmacol 20011;62:54958.

[70] Rinne JO, Anichtchik OV, Eriksson KS, et al. Increased brain histamine levels in Parkinson's disease but not in multiple system atrophy. J Neurochem 2002;81:954-60.

[71] Yokoyama H, Iinuma K. Histamine and seizures : implications for the treatment of epilepsy. CNS Drugs 1996;5:321-30.

[72] Scherkl R, Hashem A, Frey HH. Importance of histamine for seizure susceptibility. Agents Actions Suppl 1991;33:85-9. 
[73] Moher D, Liberati A, Tetzlaff J, Altman DG; PRISMA Group. Preferred reporting items for systematic reviews and meta-analyses: The PRISMA statement. J Clin Epidemiol 2009;62:1006-1012.

**[74] Ercan-Sencicek AG, Stillman AA, Ghosh AK, et al. L-histidine decarboxylase and Tourette's syndrome. N Engl J Med 2010;362:1901-8.

Analysis of linkage in a two-generation pedigree which led to the identification of a rare functional mutation in the HDC gene encoding L-histidine decarboxylase, pointing to a role for histaminergic neurotransmission in the mechanism and modulation of Tourette syndrome.

[75] American Psychiatric Association. Diagnostic and statistical manual of mental disorders: 4th edition, text revision (DSM-IV-TR). Arlington, VA. American Psychiatric Publishing, 2000.

[76] Lei J, Deng X, Zhang J, et al. Mutation screening of the HDC gene in Chinese Han patients with Tourette syndrome. Am J Med Genet B Neuropsychiatr Genet 2012;159:72-6.

[77] Fernandez TV, Sanders SJ, Yurkiewicz IR, et al. Rare copy number variants in Tourette syndrome disrupt genes in histaminergic pathways and overlap with autism. Biol Psychiatry $2012 ; 71: 392-402$.

[78] Karagiannidis I, Dehning S, Sandor P, et al. Support of the histaminergic hypothesis in Tourette syndrome: association of the histamine decarboxylase gene in a large sample of families. J Med Genet 2013;50:760-4.

**[79] Castellan Baldan L, Williams KA, Gallezot JD, et al. Histidine decarboxylase deficiency causes Tourette syndrome: parallel findings in humans and mice. Neuron 2014;81:77-90. 
Histidine decarboxylase-knockout mice exhibited potentiated tic-like behaviors, which were mitigated by the dopamine D2 antagonist haloperidol and by histamine infusion into the brain.

[80] Rapanelli M, Frick LR, Pogorelov V, et al. Dysregulated intracellular signalling in the striatum in a pathophysiologically grounded model of Tourette syndrome. Eur Neuropsychopharmacol 2014;24:1896-906.

[81] Schneider EH, Neumann D, Seifert R. Modulation of behaviour by the histaminergic system: lessons from HDC-, H3R- and H4R-deficient mice. Neurosci Biobehay Rev 2014;47:101-21.

[82] Dere E, De Souza-Silva MA, Topic B, Spieler RE, Haas HL, Huston JP. Histidinedecarboxylase knockout mice show deficient nonreinforced episodic object memory, improved negatively reinforced water-maze performance, and increased neo- and ventrostriatal dopamine turnover. Learn Mem 2003;10:510-9.

[83] Xu M, Li I, Ohtsu H, Pittenger C. Histidine decarboxylase knockout mice, a genetic model of Tourette syndrome, show repetitive grooming after induced fear. Neurosci Lett 2015;595:50-3.

[84] Shafii M. The effects of sympathomimetic and antihistaminic agents on chronic motor tics and Tourette's disorder. N Engl J Med 1986;315:1228-9.

*[85] Hartmann A, Worbe Y, Arnulf I. Increasing histamine neurotransmission in Gilles de la Tourette syndrome. J Neurol 2012;259:375-6.

Single case report showing that treatment by an inverse agonist of the H3 receptor (raising histaminergic neurotransmission) resulted in improvement in a Tourette syndrome patient's 
narcolepsy without changes in his tics, thus warranting controlled clinical trials of $\mathrm{H} 3$ receptor reverse agonists in Tourette syndrome.

[86] Erenberg G. The relationship between Tourette syndrome, attention deficit hyperactivity disorder, and stimulant medication: a critical review. Semin Pediatr Neurol 2005;12:217-21.

[87] Robertson MM. Attention deficit hyperactivity disorder, tics and Tourette's syndrome: the relationship and treatment implications. Eur Child Adolesc Psychiatry 2006;15:1-11.

[88] Jucaite A, Takano A, Boström E, et al. AZD5213: a novel histamine H3 receptor antagonist permitting high daytime and low nocturnal $\mathrm{H} 3$ receptor occupaney, a PET study in human subjects. Int J Neuropsychopharmacol 2013;16:1231-9.

[89] Bolam JP, Ellender TJ. Histamine and the striatum. Neuropharmacology 2015 in press

[90] Alsobrook JP, Pauls DL. A factor analysis of tic symptoms in Gilles de la Tourette syndrome. Am J Psychiatry 2002;159:291-6.

[91] Eapen V, Fox-Hiley P, Banerjee S, Robertson MM. Clinical features and associated psychopathology in a Tourette Syndrome cohort. Acta Neurol Scand 2004;109:255-60.

[92] Storch EA, Murphy TK, Geffken GR, et al. Further psychometric properties of the Tourette's Disorder Scale-Parent Rated version (TODS-PR). Child Psychiatry Hum Dev $2004 ; 35: 107-20$.

[93] Robertson MM, Cavanna AE. The Gilles de la Tourette Syndrome: a principal component factor analytic study of a large pedigree. Psychiatric Genet 2007;17:143-52.

[94] Robertson MM, Althoff RR, Hafez A, Pauls DL. A principal components analysis of a large cohort of patients with Gilles de la Tourette syndrome. Br J Psychiatry 2008;193:31-6. 
[95] Cavanna AE, Critchley HD, Orth M, Stern JS, Young M, Robertson MM. Dissecting the Gilles de la Tourette spectrum: a factor analytic study on 639 patients. J Neurol Neurosurg Psychiatry 2011;82:1320-3.

[96] Mathews CA, Jang KL, Herrera LD, et al. Tic symptom profiles in subjects with Tourette syndrome from two genetically isolated populations. Biol Psychiatry 2007;61:292300.

[97] Grados MA, Mathews C A, and the Tourette Syndrome Association International Consortium for Genetics. Latent class analysis of Gilles de la Tourette syndrome using comorbidities: clinical and genetic implications. Biol Psychiatry 2008;64:219-25.

[98] Rodgers S, Müller M, Kawohl W, et al. Sex-related and non-sex-related comorbidity subtypes of tic disorders: a latent class approach. Eur J Neurol 2014;21:700-7.

[99] Rapanelli M, Pittenger C. Histamine and histamine receptors in Tourette syndrome and other neuropsychiatric conditions. Neuropharmacology 2015 in press

[100] Termine C, Selvini C, Rossi G, Balottin U. Emerging treatment strategies in Tourette syndrome: what's in the pipeline? Int Rev Neurobiol 2013;112:445-80.

[101] Cavanna AE, David K, Bandera V, et al. Health-related quality of life in Gilles de la Tourette syndrome: a decade of research. Behav Neurol 2013;27:83-93.

[102] Cavanna AE, Luoni C, Selvini C, et al. Disease-specific quality of life in young patients with Tourette syndrome. Pediatr Neurol 2013;48:111-4.

[103] Conelea CA, Busch AM, Catanzaro MA, Budman CL. Tic-related activity restriction as a predictor of emotional functioning and quality of life. Compr Psychiatry 2014;55:123-9. 
[104] Yuce M, Guner SN, Karabekiroglu K, et al. Association of Tourette syndrome and obsessive-compulsive disorder with allergic diseases in children and adolescents: a preliminary study. Eur Rev Med Pharmacol Sci 2014;18:303-10. 


\section{Article Highlights}

- Tourette syndrome is a chronic tic disorder traditionally associated with alterations of dopaminergic neurotransmission, although the exact pathophysiology is still unknown.

- Other biochemical pathways, involving histaminergic neurotransmission, are likely to play a role in Tourette syndrome pathophysiology, but have received relatively little attention until recently.

- We identified a number of relevant original studies exploring the possible role of histaminergic transmission in Tourette syndrome, published over the last five years.

- Most studies focused on the role of the histidine decarboxylase gene and the potential usefulness of histidine decarboxylase knockout mice as an experimental model for studying neurochemical function in Tourette syndrome.

- Development and large-scale use of histaminergic medications deserve further research, with direct implications for the clinical management of selected Tourette syndrome phenotypes. 